\title{
A Unique SEPIC converter based Power Factor Correction method with a DCM Detection Technique
}

\author{
N. Rajasingam ${ }^{1}$, S. N. Deepa ${ }^{2}$ \\ ${ }^{1}$ Research scholar, Department of EEE, Anna University Regional Centre Coimbatore, India \\ ${ }^{2}$ Associate professor, Department of EEE, Anna University Regional Centre Coimbatore, India
}

\begin{abstract}
This paper presents a unique Single-Ended Primary Inductor Converter (SEPIC) based power factor correction method with discontinuous conduction mode detection. The SEPIC power factor correction (PFC) converter with the advent of digital control, powerful control techniques are used to achieve low-harmonic input current. An analog SEPIC based PFC converter is modified into a digitally controlled equivalent; thus provides flexibility for further implementations. The voltage and current sensing circuit design, compensator topology, the critical interrupt service routines, and the Digital Signal Processor (DSP) control is presented. The proposed SEPIC converter is contributes with a Discontinuous Conduction Mode (DCM) detection method using DSP for the purpose of power factor correction close to unity. The proposed detection technique has easy computation steps, and requires very small or almost null modification in existing SEPIC based PFC converters using DSP control techniques. The SEPIC-PFC converter analyse the effectiveness of the proposed detection approach over traditional detection techniques for power quality improvements. A new adaptive Mixed Conduction Mode (MCM) control technique is applies in the proposed SEPIC converter to realize optimal power factor and reduced total harmonic distortion contents in the output over a conventional controllers.
\end{abstract}

Keywords: DCM detection Technique, Digital Signal Processor, MCM control technique, SEPIC-PFC converter.

\section{Introduction}

In the past decade, the prevalence of energy standards and recommended practices to meet harmonic content limits has continues to attractive [1]-[3]. The development of industry regulations and recommended standards for stability of power quality leads the popularity of switched-mode power supplies to meet efficiency improvements and performance objectives [2]. The generation of harmonic contents caused by non-linear loads; high-speed active switching, capacitive, and inductive loading is undesirable effect that can lead to poor power quality implications for the utility grid [1]-[3]. Premature failure of transformers, heavy resonance interactions between equipment are caused by excessive heating by eddy currents when the harmonic current content rapidly increases. Additionally it reduces the energy supplying capacity of the utility which raises maintenance cost. A full-bridge rectifier and bulk filter capacitors are introduced in the conventional switching power supply designs.

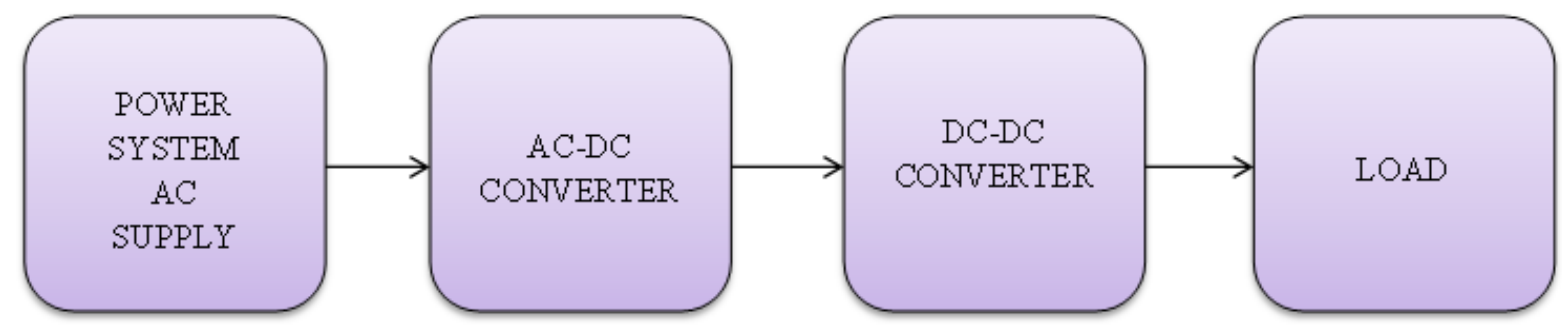

Figure 1 Typical AC-DC rectification process

Conventional power conversion methods are not suitable to obtain the recommended standards where storage components have significant limits thus the advanced switched-mode power supplies via power semiconductor devices is required [4]. A power electronic conversion achieves sustainable power quality, furthermore it obtain efficiency and transient response improvements over their passive components. Power electronic switching devices in SMPS can be operated at high switching frequencies by limiting the physical size of energy storage passive components in the circuit. The application of digital control such as limited parametric drift of energy storage components, reduced sensitivity to changes in surroundings and easy regulations for power electronic switches is an attractive option for designers to deal digital control methods over the past decade [5]-[7]. Fig. 1 shows the Typical AC-DC rectification process of the power electronics converters. The main objective of this proposed approach is to realize improvements in power quality for the 
AC/DC SEPIC based PFC converter by contributing a digital zero-current detection technique. This digital control method realizes improvements over conventional control techniques, and is subsequently suitable to the control of the proposed power factor correction, enabling enhanced power quality for SEPIC-PFC converters with a mixed conduction mode operation.

\section{Operating Principle Of The Proposed Converter}

\section{A. SEPIC BASED PFC CONVERTER:}

The Single-Ended Primary Inductor Converter based power factor correction is a basic circuit used for active power factor correction in utility grid and in switched mode power supplies, where its control strategies and performance characteristics are widely known [8]-[10]. The merits of the SEPIC converter are low current ripple, reduced cost and simple construction. The SEPIC-PFC converter as shown in the Fig. 2 is operates in high switching frequencies with a single active semiconductor switch and diode that permits a reduction in the size of the energy storage passive components such as capacitors and inductors. The supply voltage is initially rectified, then processed, and fed to the load. The major objective of power factor correction is to have a sinusoidal supply current $i_{a c}$, in-phase with the supply voltage and null harmonics contents. This objective is achieved by control of the inductor current $i_{L}$. In positive half-cycle with switching device $Q$ start to conduct and diode D reverse-biased, supply current flow s in the path of Rectifier Bridge - inductor L - active switch, and at the end it returns to the AC source via the rectifier bridge circuit. During the conduction period of the switch $\mathrm{Q}$, is a product of the duty cycle $\mathrm{d}$ and switching period $\mathrm{T}_{\mathrm{sw}}$ provides conduction duration $\mathrm{T}_{\mathrm{on}}$. During the conduction period of switch, the inductor stores the energy while capacitor discharges, supplying energy to the corresponding load.

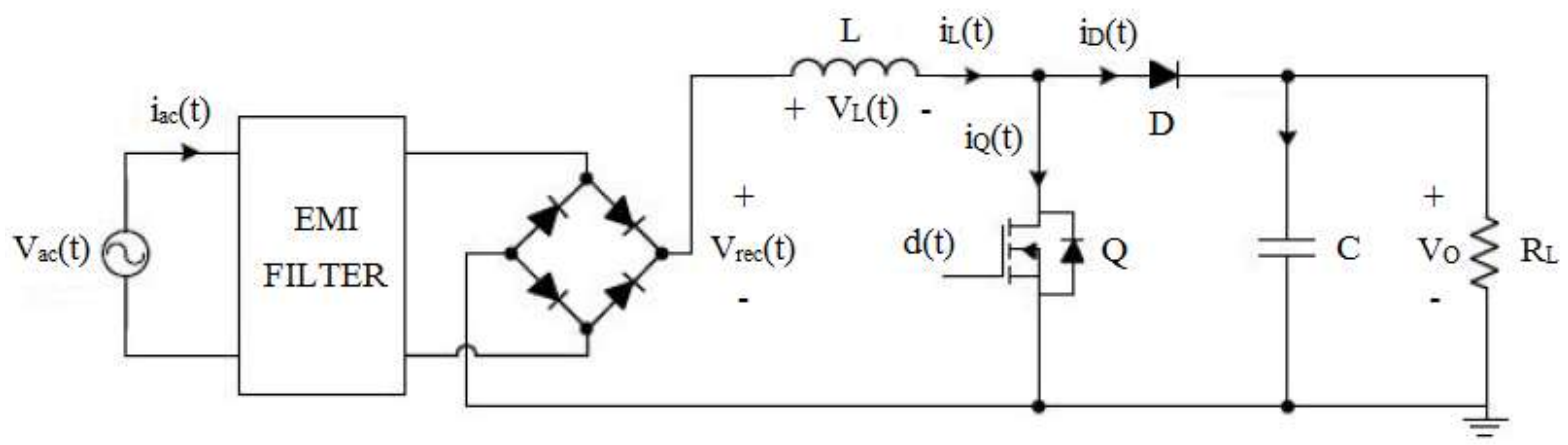

Figure 2 SEPIC based PFC Converter

When the switching device turned off, the inductor is supplying energy to the load and charging capacitor at a voltage higher than the voltage supply. The current continues to flow through bridge even the active switch is kept open. The appropriate control of switching device makes the supply current $i_{\text {ac }}$ be sinusoidal and in-phase with voltage supply $\mathrm{V}_{\mathrm{ac}}$. A constant output is obtained by controlling the duty cycle $\mathrm{d}$ to provide an average inductor current $i_{L}$ which is linearly proportional to the supply voltage. An EMI filter effectively removes the switching ripple contents from the inductor current, such that the input to the SEPICPFC converter gets only the power-factor-corrected supply current $\mathrm{i}_{\mathrm{ac}}$.

\section{B. MIXED CONDUCTION MODE:}

A switching converter can be operating in the CCM or in the DCM mode depends on the connected load basis. When the SEPIC converter operates in continuous conduction mode and discontinuous conduction mode simultaneously during a single line cycle, it is said to be mixed conduction mode (MCM) [11]-[13]. A SEPIC-PFC converter is mostly designed for CCM operation will also exhibit DCM operation near the zero crossings of the supply voltage and/or at low power output for power factor correction applications. Fig. 3 shows the waveforms of SEPIC converter during positive line input half-cycle. When a SEPIC-PFC converter designed for CCM but it operates in DCM may cause instability, higher total harmonic distortions, and poor power factor owing to the uncompensated dynamics. When a SEPIC-PFC converter designed for general CCM operation exhibits a DCM control technique during its periods in DCM, otherwise known as mixed conduction mode, lead to optimization in harmonic contents and power factor. Therefore, a converter that operates in mixed conduction mode must be designed with continuous conduction mode as well as discontinuous conduction mode control if good power quality is desired. 


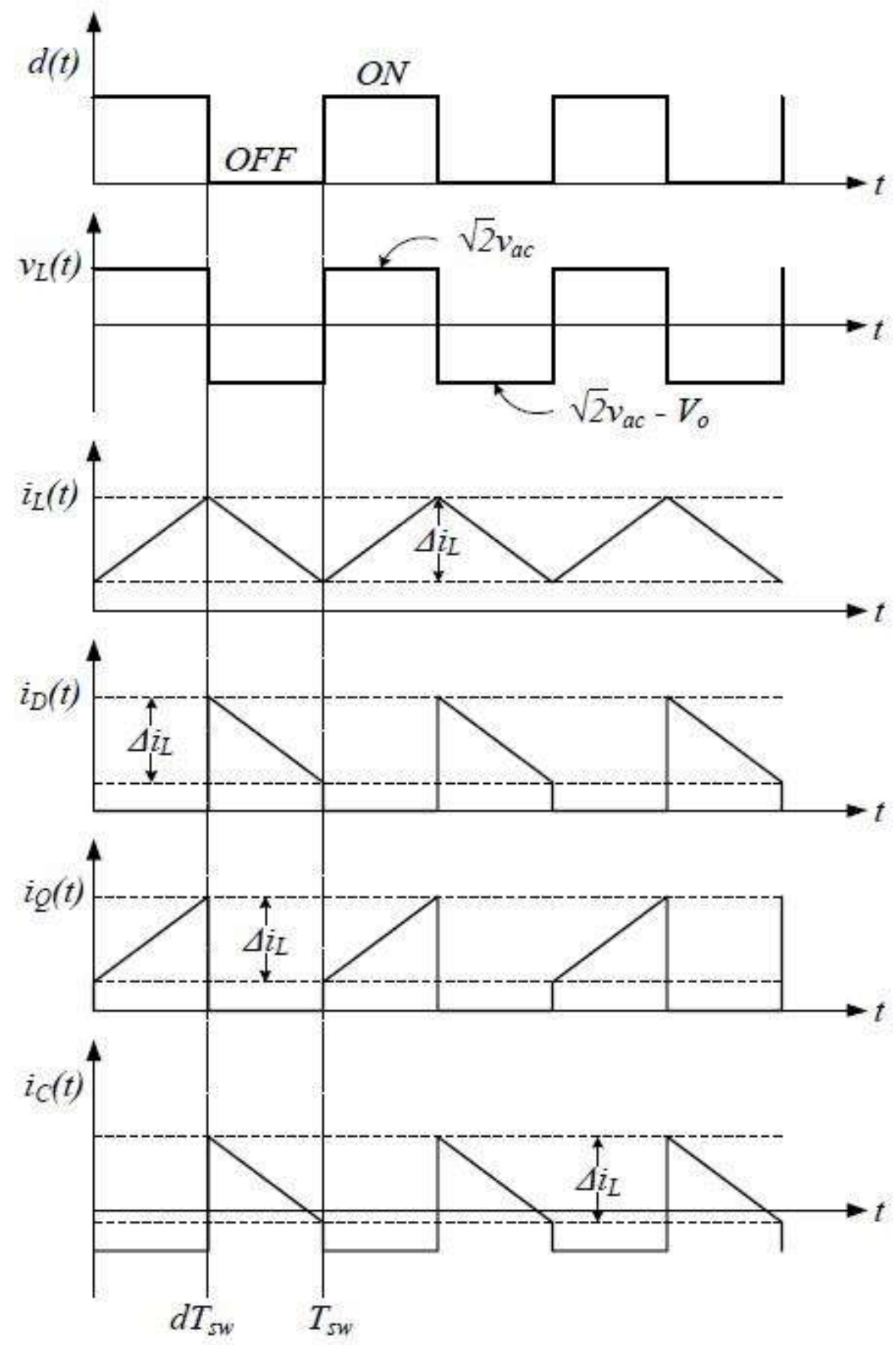

Figure 3 Waveforms of SEPIC converter during positive line input half-cycle

\section{DSP-BASED DCM DETECTION LOGIC:}

Proposed approach introduces an adaptive digital control method for the SEPIC-PFC converter under MCM operation as illustrates in Fig. 4. Specifically, the DSP-based detection logic is applied to predict the inductor current level such that the average current mode current compensator can be switched between CCM and DCM operation knowing as dual mode operation [14]-[15]. The switching characteristics of the active switches are based on the corresponding conduction mode of operation. With separate compensators designed for CCM and DCM operation considerations thereby realizing MCM control, it is possible to use the DSP based detection logic to determine the compensation topology applicable during each switching period. The switching logic is simple which requires only once the modification of the compensator parameters either CCM or DCM operation without any stability constraints. 


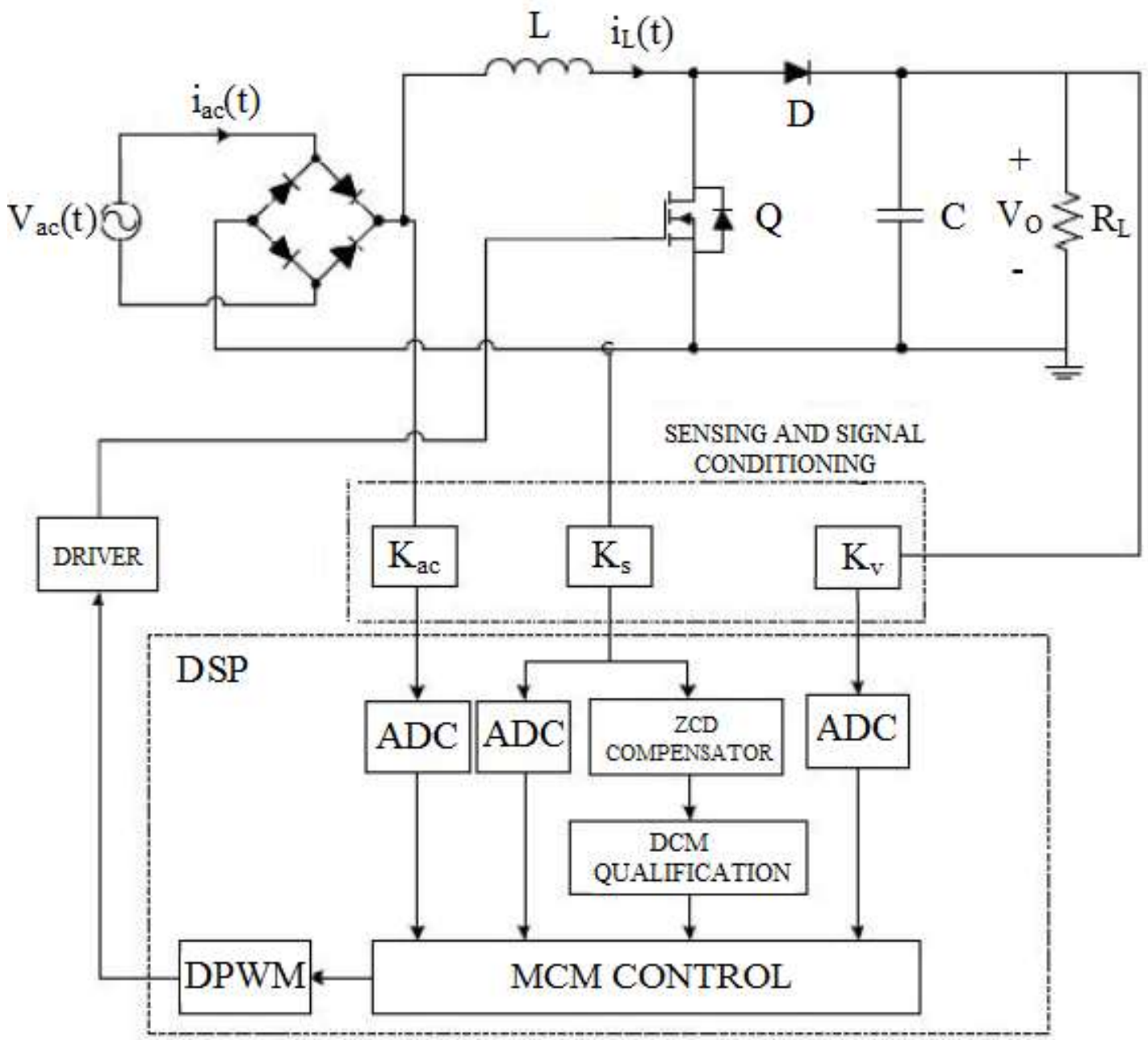

Figure 4 SEPIC with high-level digital representation of Adaptive MCM control using DSP-based DCM detection logic

The DSP will use the DCM compensator parameters in the subsequent switching cycles when the DCM flag is set at the immediate switching phase. The DSP continues with discontinuous conduction mode until the CCM flag is detected. The CCM compensator parameters are updated when the DCM flag is cleared. This approach leads sustainable operation by prevent the mode parameters from being unnecessarily updated in each switching cycle while the conduction mode of operation has not changed.

\section{Design Of The Proposed Converter}

The proposed system SEPIC converter based Power Factor Correction method with a DCM Detection Technique is simulated using MATLAB/SIMULINK. These converters have ability to continue the flow of supply current even in DCM mode of operation

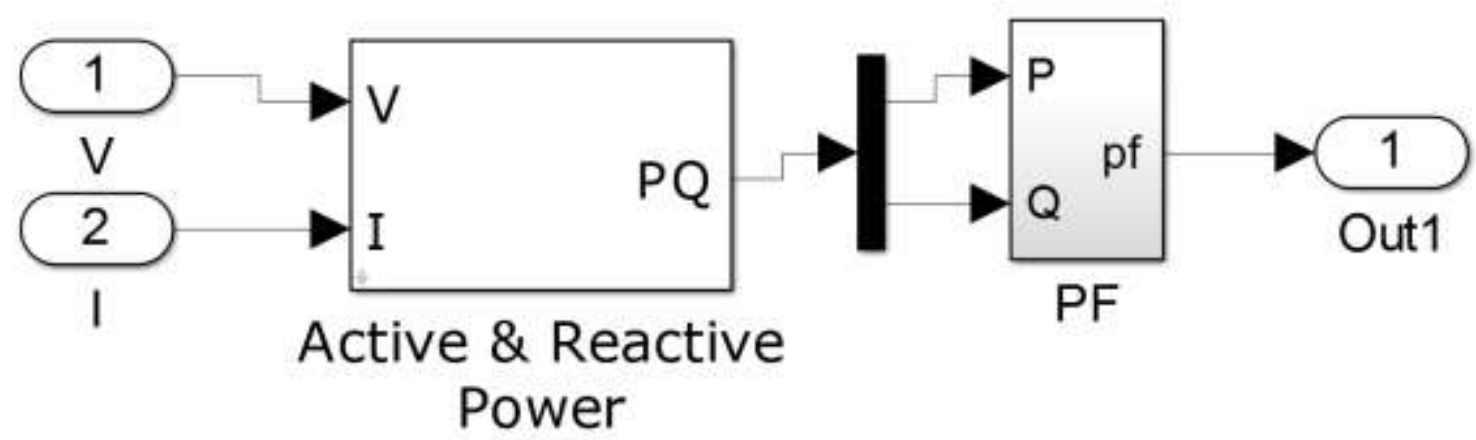




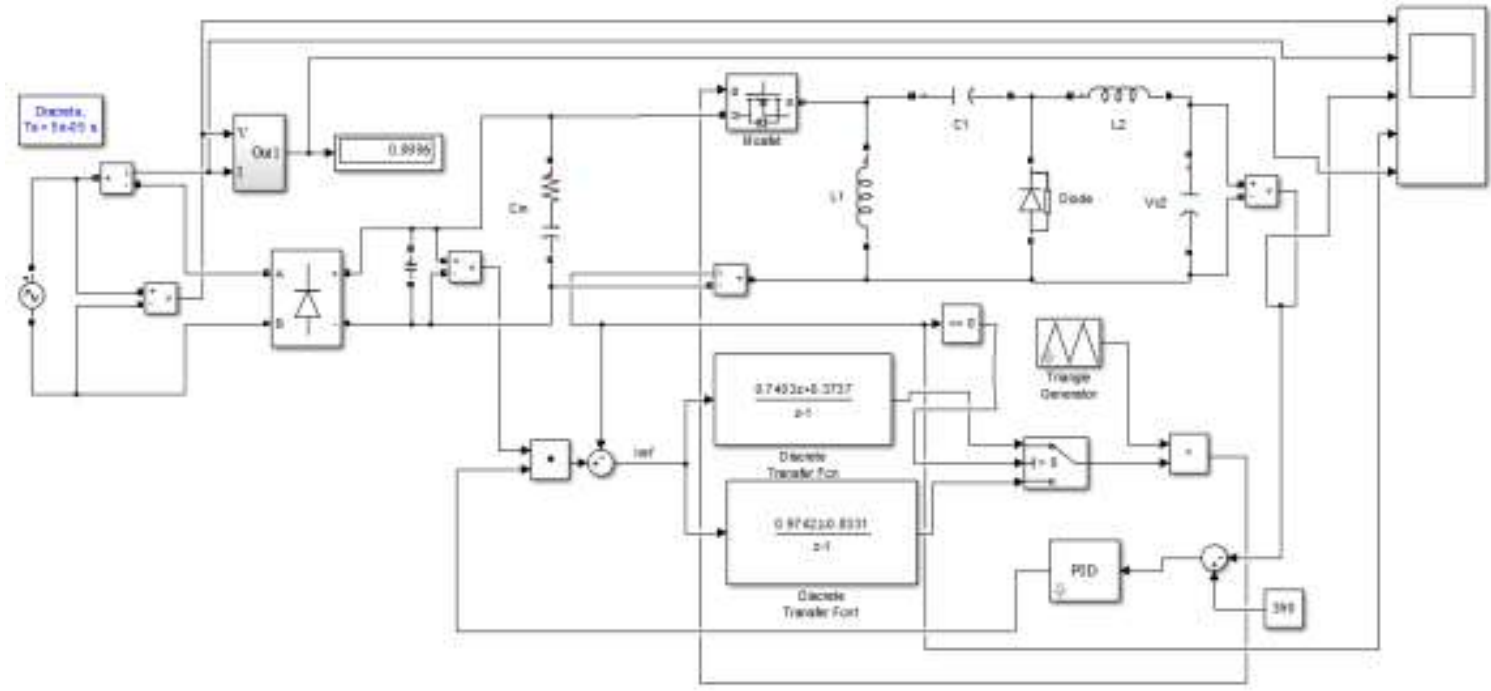

Figure 5 Simulation diagram (a) Power factor calculation (b) Digital DCM Detection and MCM Control for SEPIC converter

The circuits are drawn using SIMPOWER SYSTEM toolbox. The simulated diagrams of Power factor calculation and Digital DCM Detection and MCM Control for SEPIC converter are illustrated in the Fig. 5 (a) and 5 (b) respectively

\section{Experimental Results}

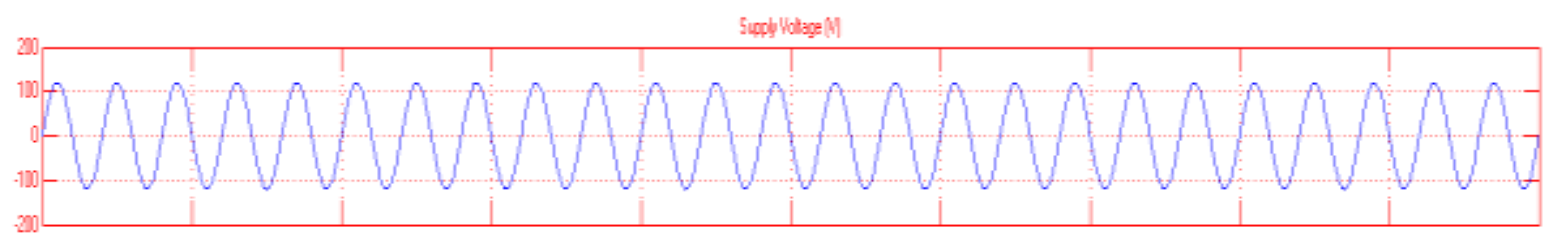

Supplanet:[]
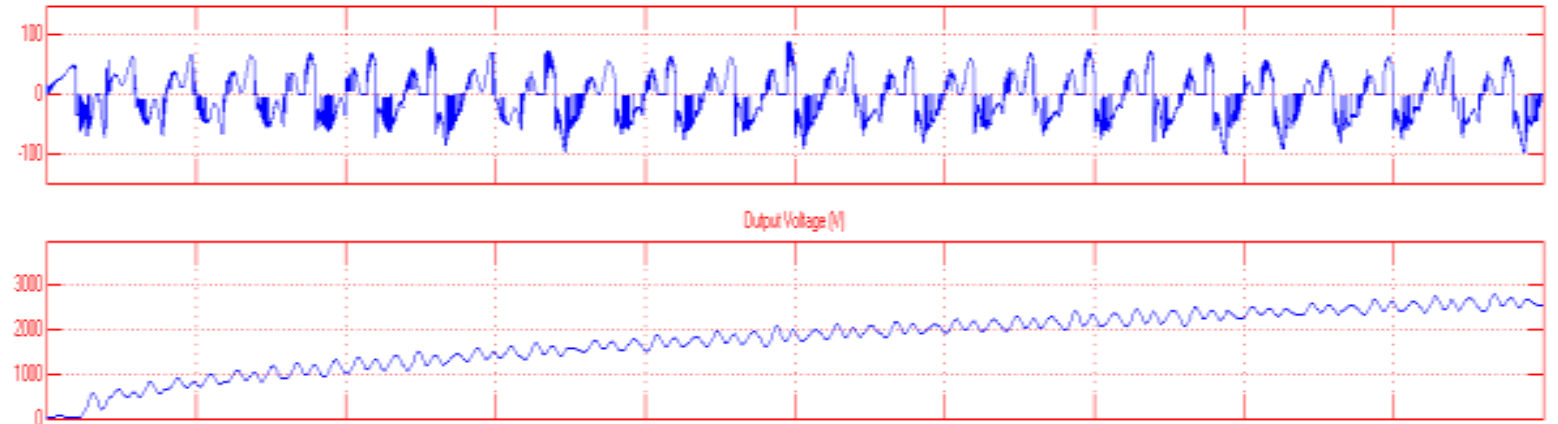

Ouput Cunet|시

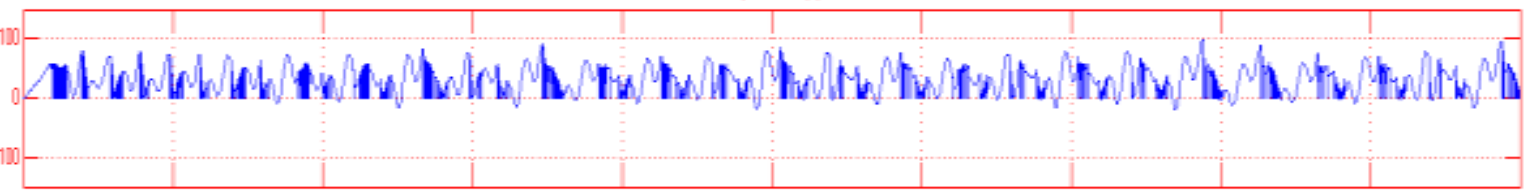

Poner Facion

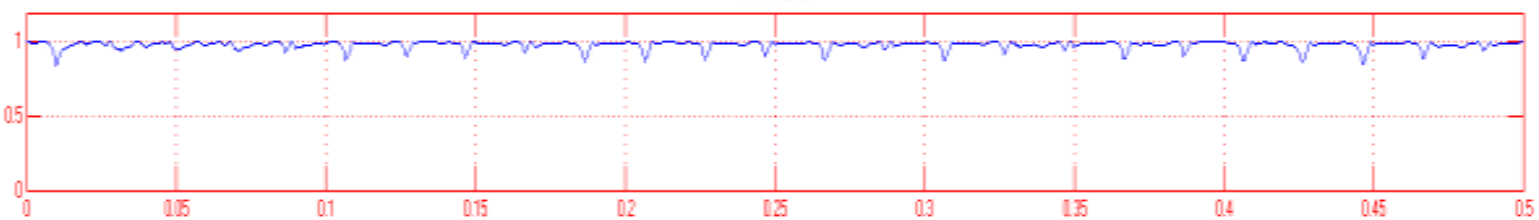

Treoffset 0

Figure 6 SIMULINK result of SEPIC - PFC converter 
Fig. 6 shows the SIMULINK result for the SEPIC converter based Power Factor Correction method with a DCM Detection Technique where the $\mathrm{x}$-axis represents time in seconds and y axis represents voltage supply, supply current, output voltage, output current and power factor respectively.

\section{Conclusion}

This paper has presented the topological principles, and experimental results for a proposed SEPIC converter. SIMULINK results demonstrate the success of modification of an Analog IC controlled SEPIC based PFC Converter and permits furthermore prototyping of digital control techniques. Output waveforms of the detection logic applied to a modified SEPIC-PFC converter provide evidence of effectiveness of this proposed approach. The proposed approach provides simplification and cost optimization over existing discontinuous conduction mode and zero crossing current detection techniques. The MCM control technique is applied to a SEPIC based power factor correction illustrates improved performance over the traditional analog IC controller and also the existing digital controller at an input voltage of $120 \mathrm{~V}$. The DSP based detection technique in the proposed converter is used to select the appropriate compensator for the estimation of the discontinuous conduction interval.

\section{References}

[1] L. Huber, Y. Jang, and M. M. Jovanovic, "Performance evaluation of bridgeless PFC boost rectifiers," IEEE Trans. Power Electron., 2008, vol. 23, no. 3, pp. 1381-1390.

[2] S. Buso, P. Mattavelli, L. Rossetto, and G. Spiazzi, "Simple digital control improving dynamic performance of power factor preregulators," IEEE Trans. Power Electron., 1998, vol. 13, no. 5, pp. 814-423.

[3] F. Chen and D. Maksimovi, Digital Control for Improved Efficiency and Reduced Harmonic Distortion Over Wide Load Range in Boost PFC Rectifiers," Power Electronics, IEEE Transactions on, 2010, vol. 25, pp. 2683-2692.

[4] T. Nussbaumer, K. Raggl and J. W. Kolar, "Design Guidelines for Interleaved Single-Phase Boost PFC Circuits," Industrial Electronics, IEEE Transactions on, 2009, vol. 56, pp. 2559-2573.

[5] A. Prodic, J. Chen, D. Maksimovic, and R. W. Erickson, "Self-tuning digitally controlled low-harmonic rectifier having fast dynamic response, ” IEEE Trans. Power Electron., 2003, vol. 18, no. 1, pp. 420-428.

[6] T. Hwang; S. Park; , "Seamless boost converter control in critical boundary condition for fuel cell power conditioning system," Energy Conversion Congress and Exposition (ECCE), IEEE, 2011, vol., no., pp.3641-3648, 17-22.

[7] K. De Gusseme, D. M. Van de Sype, A. P. M. Van den Bossche and J. A. Melkebeek, "Digitally controlled boost power-factorcorrection converters operating in both continuous and discontinuous conduction mode," Industrial Electronics, IEEE Transactions on, 2005, vol. 52, pp. 88-97.

[8] D. Lyrio Simonetti, J. Sebastian, and J. Uceda, "The discontinuous conduction mode sepic and cuk power factor preregulators: analysis and design," IEEE Transactions on Industrial Electronics, 1997, vol. 44, no. 5, pp. 630-637.

[9] G. Tibola and I. Barbi, "Isolated three-phase high power factor rectifier based on the sepic converter operating in discontinuous conduction mode," IEEE Transactions on Power Electronics, 2013, vol. 28, no. 11, pp. 4962-4969.

[10] M. Mahdavi, H. Farzanehfard, "Bridgeless SEPIC PFC rectifier with reduced components and conduction losses", IEEE Transactions on Industry Applications, 2011, vol. 47, no. 2, pp. 873 - 881.

[11] Tripathi, R.K.; Das, S.P.; Dubey, G.K., "Mixed-mode operation of boost switch-mode rectifier for wide range of load variations," Power Electronics, IEEE Transactions on , 2002, vol.17, no.6, pp. 999- 1009.

[12] X. Zhang and J. W. Spencer, "Analysis of Boost PFC Converters Operating in the Discontinuous Conduction Mode," Power Electronics, IEEE Transactions on, 2011, vol. 26, pp. 3621-3628.

[13] K. De Gusseme, D. M. Van de Sype, A. P. M. Van den Bossche and J. A. Melkebeek, "Input-Current Distortion of CCM Boost PFC Converters Operated in DCM," Industrial Electronics, IEEE Transactions on, 2007, vol. 54, pp. 858-865.

[14] W. Zhang, G. Feng, Y. Liu, B. Wu, "A digital power factor correction (PFC) control strategy optimized for DSP," Power Electronics, IEEE Transactions on, 2004, vol. 19, pp. 1474-1485.

[15] J. Zhou, Z. Lu, Z. Lin, Y. Ren, Z. Qian, and Y. Wang, "Novel sampling algorithm for DSP controlled 2kW PFC converter", IEEE Trans. Power Electron., 2001, vol. 16, pp.217 -222. 